\title{
MADRES SOLTERAS POR ELECCIÓN: REPRESENTACIONES SOBRE LA FECUNDACIÓN SEXUAL COMO VÍA DE ACCESO A LA MATERNIDAD
}

\author{
SINGLE MOTHERS BY CHOICE: REPRESENTATIONS OF SEXUAL \\ INTERCOURSE AS A MEANS TO MOTHERHOOD
}

\author{
María Isabel Jociles Rubio ${ }^{1}$ y Fernando Villaamil Pérez ${ }^{1}$
}

\begin{abstract}
Se analiza el discurso sobre las motivaciones que las Madres Solteras por Elección (MSPE) madrileñas aducen para optar o no por la fecundación sexual como vía de acceso a la maternidad. Este discurso, producido en entrevistas cualitativas y en otros contextos de interacción que han sido objeto de observación participante, revela que las MSPE distinguen dos formas de construir sus familias mediante la fecundación sexual: una es "el engaño" (mantener relaciones orientadas subrepticiamente al embarazo) y la otra consiste en recurrir a un "donante conocido" (a un varón con quien se pacta que no reclamará la paternidad sobre el hijo que nazca). La primera es objeto de una fuerte reprobación moral, y la segunda conlleva serios riesgos para conservar la autonomía del proyecto familiar, por lo que las MSPE estudiadas cuestionan que se siga optando por ellas en unos tiempos en que otras alternativas están al alcance de las mujeres que escogen ser madres solteras.
\end{abstract}

Palabras claves: madres solteras por elección (MSPE), monoparentalidad, fecundación sexual, donante conocido.

This article analyzes the discourse surrounding motivations that Single Mothers by Choice (SMC) of Madrid, Spain, provide for choosing whether to use sexual intercourse as a path to single parenthood. The discourse produced in qualitative interviews, as well as participant interactions and observations, shows that SMC have two ways to build their families using sexual intercourse. One way, called "the deceit", is to use sexual intercourse to become surreptitiously pregnant, and the other is to use a "known donor" or a man who agrees not to claim paternity of the child they produce. The first is morally disapproved of, and the second entails serious risks to preserving the autonomy of the SMC. Consequently, the SMC interviewed question whether they should continue to opt for these avenues to single parenthood at a time when other alternatives are available to the women.

Key words: Single mothers by choice (SMC), single parenthood, sexual reproduction, known donor.

Los resultados que se presentan en este artículo provienen de una investigación etnográfica que lleva por título "Madres solteras por elección: proyectos familiares y políticas públicas" ${ }^{\text {, }}$ con la que hemos abordado algunas dimensiones de un fenómeno hasta ahora poco estudiado en España así como en el ámbito latinoamericano: el de la monoparentalidad por elección. Como se destaca en Jociles y Rivas (2009), se trata de un fenómeno que, si bien ha gozado de una considerable atención por parte de los medios de comunicación en los últimos años, apenas ha sido objeto de estudios científico-sociales $^{2}$, a diferencia de lo que ha sucedido en el ámbito anglosajón o, incluso, en el israelí (véase Ben-Ari y Weinberg-Kurnik 2007;
Bock 2000; Branham 1979; Groze 1991; Davies y Rains 1995; Dougherty 1978; Hertz 2006; Hertz y Ferguson 1998; Mannis 1999; Potter y Knaub 1988; Shireman 1995 y 1996; Siegel 1995, 1998). Según los datos con que contamos, aparte de la nuestra, sólo se han llevado a cabo en España dos investigaciones sociales más en torno a las madres solteras por elección (de ahora en adelante, MSPE): una tesis doctoral leída en la Universidad de Barcelona (Jordana 2007) y un trabajo realizado por un equipo de la Universidad de Sevilla (González et al. 2008). Ambos se ocupan de subrayar los proyectos familiares de las MSPE como modelos emergentes y como formas de empoderamiento de las mujeres en las sociedades contemporáneas.

1 Departamento de Antropología Social, Universidad Complutense, Madrid, España. jociles@cps.ucm.es; villaamil@cps.ucm.es. 
En cuanto a América Latina, conocemos el surgimiento de estos modelos familiares en países como Brasil, Argentina, México y Chile, de modo que en foros on-line en lengua castellana como los llamados Madres Solteras por Elección y Adoptarsiendosoltero, que han sido creados por y para ellas, hay una participación regular de MSPE de estos países, sobre todo argentinas.

Ello no se ha plasmado en un interés parejo de las ciencias sociales latinoamericanas por estudiar este fenómeno. No obstante, en Brasil, donde recibe el nombre de produção independente cuando alude a la maternidad biológica, hallamos una tesis doctoral temprana, la de la antropóloga Tania Dauster, quien la defiende en 1987 en la Universidad Federal de Río de Janeiro, y algo más tarde, los artículos de Ana Maria Szapiro y Terezinha Féres-Carneiro (2002), de Eduardo Leite (2003) y de María Amelia Castagno (2008), el primero planteado desde la psicología y los otros dos desde el derecho. El tercero trata sobre "los conflictos jurídicos" que, en opinión de Castagno, surgen entre tres derechos reconocidos por la legislación brasileña: el de la mujer sin pareja a planear una familia monoparental, el del hijo/a a que se determine quién es su padre y el del donador de gametos al anonimato. Partiendo de la premisa de que la ausencia de un padre tiene ineludibles efectos negativos sobre el niño/a y de que el derecho de éste/a debe ser priorizado sobre los derechos de la madre o del donador, vaticina que de seguir "permitiendo que este tipo de realidad [el de la familia monoparental sin padre] siga existiendo, la sociedad brasileña estará condenada a convivir con adultos problemáticos e infelices" "(Castagno 2008:163); vaticinio que, por cierto, no busca apoyar en estudios empíricos sobre el tema, sino tan sólo en la obra -antes citada- de Leite. En lo que se refiere a Szapiro y Féres-Carneiro, sobre la base de entrevistas efectuadas a MSPE por fecundación sexual pertenecientes a las clases medias urbanas que, en consonancia con el discurso feminista de su generación, consideran la independencia y la libertad como elementos fundamentales de sus proyectos vitales, estas autoras sostienen que la produção independente debe ser entendida como un intento de construir un nuevo lugar para las mujeres a partir del reconocimiento de la maternidad, es decir, de una "antigua marca cultural", como cuestión femenina pero sometida al ethos propio de las sociedades actuales.
En Argentina conocemos el trabajo de Marisa Herrera y Verónica Spaventa (2004), alusivo a las MSPE que escogen la adopción para conformar su familia monoparental. Ambas juristas, a través de un análisis del discurso que se desprende de las sentencias judiciales, mantienen que las mujeres solas que quieren adoptar son objeto de discriminación con respecto a las parejas; lo que tiene lugar paralelamente a un proceso que denominan "desmonoparentalidad", por cuanto los niños que son entregados en adopción provienen de manera predominante de familias monoparentales encabezadas por mujeres; ello como consecuencia, según concluyen, de que "en el campo jurídico no se ha logrado aún quebrar con el paradigma monolítico de la familia tradicional" y de que permanezcan en él, por consiguiente, "prejuicios que giran en torno a otras manifestaciones familiares" (Herrera y Spaventa 2004:1). Por último, sabemos -por comunicación personal- que Irene Calvo Agoglia, psicóloga de la Universidad Alberto Hurtado de Chile, está desarrollando un estudio sobre las MSPE que optan por la adopción; del que, sin embargo, todavía no se han derivado publicaciones.

Así, las investigaciones efectuadas en América Latina sobre la monoparentalidad por elección o, en particular, sobre algunas de las vías de acceso a la misma (fecundación sexual, reproducción asistida o adopción) son más bien reducidas, al igual que-como se ha dicho- sucede en España, debido seguramente a que se trata de una forma familiar que, en lo que respecta al menos a su visibilidad, es emergente. A pesar de todo, los estudios existentes nos ponen sobre la pista de que se están produciendo profundos cambios en las estructuras familiares de la región, en especial en las correspondientes a las clases medias, como consecuencia de las transformaciones legislativas, tecnológicas (acceso a la reproducción asistida), socioeconómicas (educación, incorporación al trabajo remunerado, etc.) y culturales (valores asociados al individualismo -Alberdi 1999; Beck y Beck-Gernsheim 2003; Dumont 1987; Inglehart 1990; Jiménez 2005-) que, a la par que permiten separar sexualidad, reproducción y filiación, abren nuevas posibilidades de vida principalmente para las mujeres.

Transformaciones que han incidido en la mayor presencia en España, país al que se refiere el estudio sobre las MSPE que aquí se presenta, de hogares no convencionales (recompuestos, "sin núcleo", parejas sin hijos, homoparentales... ${ }^{3}$ ) y, en particular, de 
hogares monoparentales. Así, entre 1991 y 2001 (último periodo sobre el que disponemos de datos censales de este tipo), los hogares españoles que más crecen son los formados por madres o padres solos con hijos y "con otras personas" (135,6\% y $62,1 \%$, respectivamente), o sea, por núcleos monoparentales complejos, aumentando asimismo significativamente los hogares constituidos por núcleos monoparentales simples ("sin otras personas"), por lo que el incremento del conjunto de la monoparentalidad, casi del $48 \%$, es uno de los aspectos más destacables de la década. De hecho, los núcleos monoparentales, simples y complejos, alcanzan un total de 1.412.400 hogares en cifras absolutas y representan, en 2001, alrededor del $10 \%$ de todos los hogares españoles; el $80 \%$ de los cuales (1.130.000, aproximadamente) están encabezados por mujeres (INE 2004).

Sin duda, a partir de datos censales, no puede saberse qué número de hogares no convencionales corresponden a MSPE, ni siquiera tomando en consideración únicamente los hogares monoparentales encabezados por mujeres, sobre todo porque el Censo no posibilita distinguir si la monoparentalidad ha sido planeada y originaria (es decir, no ha sido "accidental" ni "sobrevenida" tras una separación o divorcio), criterios básicos para identificar al colectivo. Sin embargo, las cifras aportadas por González et al. (2008:7-8) permiten estimar que las MSPE han ido en alza en la medida en que ha ocurrido lo mismo con el conjunto de las madres solteras, dado el incremento notable experimentado por los hijos nacidos de éstas, que han pasado del $2,03 \%$ en 1975 al $26 \%$ en 2005 . Y si atendemos a las madres solteras de 35 o más años, para así tener mayor seguridad de que estamos hablando de mujeres adultas y maduras (cual es el caso de las MSPE), el crecimiento en los últimos 20 años ha sido espectacular: la maternidad de las solteras de este grupo de edad ha subido más de un $300 \%$, pasando de un $6,3 \%$ en 1985 a un $20,5 \%$ en 2005.

Además de cambios socioeconómicos, culturales y tecnológicos como los enumerados más arriba, los cambios legislativos emprendidos desde el último cuarto del siglo pasado son especialmente relevantes para explicar el peso creciente que las MSPE (y, en general, los hogares no convencionales) adquieren en la sociedad española. Entre estos cambios legislativos, podemos mencionar los siguientes:
(1) La legalización de los métodos anticonceptivos mediante la modificación en 1978 del artículo 416 del Código Penal. Ello supuso un paso importante en el proceso de normalización de la situación de la mujer y de las familias españolas, gracias a la separación entre sexualidad y procreación. Además, cuando el control de la concepción es posible, como dice Tort (1995), varían en concomitancia las condiciones de emergencia del deseo de maternidad o, como asegura Badinter (2011:163), la maternidad deja de ser "una evidencia natural" para convertirse en "un tema", es decir, en una elección.

(2) Como desarrollo del artículo 39 de la Constitución Española, se aprueba en 1981 la Ley de Reforma del Código Civil en materia de filiación, patria potestad y régimen económico del matrimonio, que anula la distinción entre hijos legítimos e ilegítimos equipándolos en sus derechos. La Ley de 2005, por la que se modifica el reglamento del Registro Civil, elimina posteriormente la obligación de anotar el nombre (real o ficticio) del padre en todo registro de nacimiento, lo que contribuye a preservar la intimidad de aquellas madres solteras que no desean dejar constancia de la identidad del otro progenitor y, en términos generales, a normalizar la monoparentalidad.

(3) La Ley 14/2006 sobre reproducción asistida (a la que anteceden la Ley 35/1988 y la Ley 45/2003) reconoce el derecho de toda mujer mayor de 18 años y con plena capacidad de obrar, independientemente de su estado civil y de su orientación sexual, a ser receptora o usuaria de las técnicas reguladas en ella; recogiendo asimismo que la inscripción del hijo/a en el Registro Civil no reflejará datos de los que se pueda inferir cómo ha sido engendrado, evitando así cualquier tipo de discriminación del menor nacido mediante dichas técnicas. Esta normativa exige que la donación de gametos (espermatozoides u óvulos) sea anónima, salvo cuando se utiliza semen del marido (o pareja estable) de la mujer en cuyo útero se implanta el óvulo fecundado.

(4) La regulación de la adopción ha sido objeto de sucesivas reformas desde su redacción originaria en el Código Civil de 1889 (Ley de abril del 1958, Ley 7/1970, Ley 11/1981, Ley 21/1987 reformada por Ley Orgánica 1/1996 de Protección Jurídica del Menor y, por último, Ley 54/2007 de Adopción Internacional), 
respetándose en todas ellas el derecho a acceder en solitario a la maternidad adoptiva.

(5) Hay que mencionar también, por último, la Ley 39/1999 para promover la conciliación de la vida familiar y laboral de las personas trabajadoras, en la que se contempla la adopción y el acogimiento entre las situaciones que dan derecho a la baja por maternidad sea cual sea la estructura familiar de esas personas (monoparental o biparental).

Estos cambios y transformaciones han potenciado la libertad de los sujetos y, particularmente, de las mujeres en la configuración de sus proyectos familiares (Héritier 2007:25-28), como ha ocurrido con las madres solteras que han optado, de manera deliberada y planificada, por constituir en solitario una familia a través de la adopción internacional, la procreación asistida y/o la fecundación sexual (es decir, con las MSPE). Estos proyectos se han visto reforzados por una "retórica de la igualdad" (presente en la política, los medios de comunicación, la vida pública, el sistema educativo, entre otros) que cuestiona la polaridad de los géneros y propugna en su lugar los mismos derechos y oportunidades, haciendo posible así la diversidad y pluralidad de estilos de vida, personales y familiares (Rivas et al. 2011:123-125).

Nuestra investigación, desarrollada en la Comunidad de Madrid (España), ha tenido como objetivo explorar las representaciones que las MSPE elaboran acerca de las distintas maneras de constituir un proyecto monoparental planeado en cuanto tal. Aquí presentamos los resultados obtenidos al respecto, pero sólo en la medida en que hacen referencia a las representaciones que estas mujeres, al margen de la vía de acceso a la maternidad que hayan seguido, manejan acerca de la fecundación sexual, es decir, de una sola de ellas $^{4}$. Se trata de representaciones que emergen especialmente cuando las MSPE abordan el tema de las motivaciones, propias y ajenas, para escoger o rechazar esa manera de llegar a ser madres sobre cualesquiera de las otras, de ahí que los discursos que analizamos en las páginas que siguen sean los alusivos a dichas motivaciones.

Exponemos, en primer lugar, la metodología utilizada para producir los datos en los que se apoya empíricamente el artículo; en segundo lugar, abordamos los resultados referidos al tema central de éste, es decir, a las representaciones de las MSPE sobre la fecundación sexual como vía de acceso a la maternidad en solitario, distinguiendo entre las dos submodalidades que ellas mismas reconocen (el "ir de caza" y el "donante conocido"); y, por último, incluimos un apartado de Conclusiones.

\section{Metodología}

En el contexto de la investigación etnográfica con la que hemos dotado de base empírica a este artículo, hemos realizado 52 entrevistas cualitativas a MSPE madrileñas: 33 de ellas son mujeres que han adoptado y/o están en proceso de adopción (en 32 casos, internacional y en 1, nacional), 16 han acudido a las técnicas de reproducción asistida, 2 de las cuales han hecho uso asimismo de la adopción para intentar tener a su primer o segundo hijo, y 3 han recurrido a la fecundación sexual con "donante conocido" (ver tabla 1).

Asimismo, durante el trabajo de campo (mayo de 2007 y, sobre todo, el periodo enmarcado entre enero de 2008 y agosto de 2009), hemos recogido datos mediante observación sistemática (con una media de una hora de observación al día) en los foros de Internet ya mencionados: Madres Solteras por Elección (http://madremspe.multiply.com) y Adoptarsiendosoltero (http://es.groups.yahoo. com/group/ adoptarsiendosoltero); hemos asistido a eventos de formación postadoptiva organizados o sufragados por la Comunidad de Madrid; hemos acudido a encuentros de carácter informal entre grupos restringidos de MSPE que son amigas entre sí, así como a diversas kedadas, esto es, a las reuniones presenciales de algunas de aquellas comunidades virtuales, realizando observación participante durante las mismas. Finalmente, hemos recopilado información documental derivada de diversas fuentes: manuales de evaluación de la idoneidad y guías de formación de padres adoptivos, resúmenes estadísticos, así como blogs y webs creados por MSPE residentes en el mencionado ámbito territorial.

Estos foros y lugares de encuentro también han servido, al igual que los contactos personales de algunos miembros del equipo de investigación, para acceder a la muestra de MSPE a entrevistar, pues las peticiones de colaboración llevadas a cabo en estos espacios y redes sociales han constituido los principales medios a través de los cuales se las ha contactado o, cuando no, han sido el punto de arranque para la implementación del sistema de 
"bola de nieve". Las MSPE entrevistadas han sido las que se han definido a sí mismas como tales al responder a nuestra llamada de colaboración; y si analizamos el perfil que presentan las 52 que, tras responder a ella, terminaron componiendo la muestra, hallamos que aparte de ciertas características socioeconómicas ya resaltadas en otros trabajos (se convierten en madres a edades maduras, tienen un elevado nivel académico, son económicamente solventes, se inscriben en las clases medias-altas, etc.), todas comparten un conjunto de rasgos que nos permiten conocer cómo se autodefinen. Así, las MSPE que hemos estudiado quedan fuera de la denominada monoparentalidad sobrevenida (de divorciadas, separadas o viudas que se hacen cargo de los hijos tras haberse roto un hogar biparental), es decir, de los casos -los más frecuentes entre las familias monoparentales- en que no ha habido una voluntad "originaria" de desarrollar un proyecto familiar en solitario. Tampoco responden a aquellos otros casos en que la monoparentalidad no ha sido buscada de modo expreso (y es tildada por ello de accidental), aunque haya sido plenamente asumida una vez que la mujer se ha quedado embarazada. En suma, nuestra población de MSPE está constituida por mujeres que han planeado una maternidad en solitario, por lo cual su modelo familiar puede ser calificado de monoparentalidad originaria y, salvando una excepción (la de $\mathrm{Cristal}^{5}$ ), planeada.

\section{Resultados}

\section{"Ir de caza": Imágenes sobre las MSPE que acuden a la Fecundación Sexual no Declarada}

No hemos conseguido acceder a MSPE que hayan concebido a través de relaciones sexuales orientadas ex profeso, pero de forma no declarada, a quedarse embarazadas. Ello podría tener que ver, sin duda, con que existen pocos casos que se correspondan con esta vía de acceso a la maternidad, cuestión que, sin embargo, resulta casi imposible de verificar en la medida en que la dificultad para llegar hasta estas mujeres se convierte a la vez en obstáculo para cuantificar su número. De hecho, cuando llevábamos realizadas unas 40 entrevistas, debido a que ninguna de las entrevistadas casaba con la modalidad de fecundación sexual, nos dirigimos de nuevo a ellas preguntándoles si conocían a alguna mujer que hubiera acudido a esta vía ya fuera de manera pactada o subrepticia, y les pedimos su cooperación para cooptarla para el estudio. Quienes respondieron a nuestra demanda manifestaron o bien que no conocían a mujeres con esas características o bien, cuando sí las conocían, que no se atrevían a trasladarles nuestra petición puesto que ellas no les habían revelado cómo habían accedido a la maternidad, de modo que ello era objeto de sospecha o de rumor antes que algo realmente sabido.

Estas MSPE, por otra parte, frente a las que han tomado otras opciones, no cuentan con plataformas colectivas propias, más o menos institucionalizadas (tales como foros, grupos de Internet, asociaciones, etc.), que las agrupen, como tampoco se integran en otras de carácter más general en donde se facilitara su visibilidad y, por consiguiente, también la posibilidad de llegar hasta ellas. Como antes se ha expuesto, en España hay dos comunidades virtuales dirigidas específicamente a MSPE (en las que participan, por supuesto, las que residen en la Comunidad de Madrid): se trata, por un lado, de Adoptarsiendosoltero, que reúne a un buen número de mujeres (así como de hombres) que han adoptado o están adoptando en solitario y, por otro, de la que se conoce precisamente como Madres Solteras por Elección, que se dirige, al menos sobre el papel, a todas las MSPE. Aunque es cierto que esta segunda comunidad está compuesta sobre todo por mujeres que recurren a la fecundación asistida, también lo es que, desde un principio, se les reservaron espacios concretos a las que optan por la "adopción" o por el "donante conocido", no así, en cambio, a las que se decantan por la fecundación sexual no declarada. Es más, cuando alguna de estas últimas ha querido intervenir en el foro on-line de la comunidad exponiendo o defendiendo su opción, enseguida se le ha hecho saber que éste no era el lugar para ello e incluso, en alguna ocasión, se la ha banneado, expulsándola por incumplir los requisitos de participación.

La previa declaración (o no) de la intención de concebir, con la consecuente estipulación (o no) de pactos entre los progenitores que hagan referencia a las responsabilidades y a los roles que cada uno se compromete a asumir con respecto al nasciturus, establece una diferencia relevante en las formas de la fecundación sexual. Es lo que, desde la perspectiva de las MSPE, marca la distinción entre el "ir de caza" y la opción del "donante conocido"; distinción que conciben como fundamental por mucho que, en los dos casos, se recurra a un mismo método objetivo: la fecundación sexual planificada. 
Así, mientras que la opción del "donante conocido" tiene cabida entre las MSPE y goza de legitimidad entre ellas (aunque -por los motivos que se verán- no se considere recomendable), no ocurre lo mismo con el "ir de caza" o el "engaño", nombres con los que es calificada la situación en que a un hombre se le oculta la intención de la relación sexual y, de este modo, no se habla con él acerca de "los objetivos" implicados en ella. Es decir que, cuando media esta situación, el genitor ya no es considerado "donante" sino alguien al que se "engaña" para engendrar un hijo/a sin contar con su consentimiento o, en ciertos casos, para "atraparle" mediante el subterfugio de un embarazo simuladamente accidental que, cuando no logra su meta, se disfraza a posteriori de monoparentalidad electiva.

El "ir de caza" es, de esta manera, fuertemente censurado por las MSPE, considerado deleznable desde un punto de vista ético-moral por lo que conlleva de instrumentalización de otra persona, ya se trate de un conocido o de un desconocido. Cuando se argumenta el rechazo del "engaño" a un desconocido, a las razones ético-morales antes expuestas, se superponen además otras de carácter sanitario, relacionadas con la prevención de riesgos para la salud tanto de la madre como del hijo. Así, practicar sexo desprotegido con quien se desconoce, por añadidura, su seroestatus constituye una insensatez y un despropósito en "los tiempos del Sida", según las palabras de Angelina, o "ir de loca por la vida", para usar las de Lali, otra de las entrevistadas. A la vez, recurrir a la fecundación sexual con un desconocido supone no prever que si éste transmite al niño/a alguna enfermedad de origen genético o si el hijo/a precisa de una "donación de órganos normales", no se le podrá localizar después de cara a hacer frente a estas situaciones:

Nosotros no conocemos al donante, como (sucede en) una donación de órganos normales, pero en caso de que el niño desarrollara una enfermedad en la que hubiera que ver si el padre era compatible o no con él para ayudarle en esa enfermedad, tanto la clínica como un juez pueden contactar con él y, entonces, digamos que en ese sentido mi niño está cubierto. A mí me da mucho miedo la gente que se lanza a decir: "iVenga! Una noche loca con uno que no conozco" que, primero, desde el punto de vista de salud, no sabes lo que te pueden pegar, y luego es eso: no le conoces, no tienes ninguna referencia para tu hijo (Crista, 30-35 años, soltera, estudios universitarios, ingeniera, reproducción asistida).

"Engañar a un hombre", sea éste quien sea, es tanto más inadmisible cuanto que hoy en día se dispone de una gama de alternativas lo suficientemente amplia como para que no se justifique el que una mujer se sirva de esta estratagema para llegar a ser madre.

Cuando te planteas esto, piensas todas las opciones habidas y por haber. Lo de engañar a un hombre lo descarté inmediatamente porque no me parecía ético. Creo que si defendemos nuestros derechos, tenemos que defender nuestras obligaciones y las de ellos. Si la otra persona no está de acuerdo, ¡no está de acuerdo! Y más ahora que tienes tantas facilidades. Además, eso va en tu contra. A mí me gusta ir siempre con la verdad: ¿cómo le cuentas a un niño que engañaste a una persona? Éticamente no me parecía correcto. (Rosaura, 40-45 años, soltera, estudios universitarios, periodista, una hija de 5-10 años por reproducción asistida).

Una actitud contraria a "ir de caza" la encontramos -como se ha visto- en los discursos de nuestras entrevistadas, en las intervenciones de MSPE en foros on-line como los antes mencionados ... y también en estudios realizados en el ámbito anglosajón, como el de Murray y Golombok (2005:251), cuyas entrevistadas enfatizaron también la inaceptabilidad ético-moral de esta opción, al igual que lo habían hecho antes otras mujeres estudiadas en ese mismo ámbito geográfico-cultural (Klock et al. 1996; Mechanek et al. 1988). La fecundación sexual planificada no declarada se sitúa, de hecho, en el peldaño inferior de la que puede ser llamada "escala de explicabilidad" de las distintas vías de acceso a la maternidad en solitario "“¿cómo le cuentas a un niño que engañaste a una persona?", se preguntaba Rosaura retóricamente más arriba), que no deja de ser simultáneamente una escala de legitimidad social. Y esto es así también porque, si se contempla desde el punto de vista de Castagno (2008) expuesto más atrás, el "ir de caza" es una opción que no permite compatibilizar los derechos de 
la mujer (a tener un hijo/a y a preservar la autonomía de su proyecto familiar), del hijo/a (a conocer su origen $^{6}$ ) y del genitor (en este caso, a conocer que ha engendrado un hijo/a).

En suma, la dificultad que hemos tenido para localizar a MSPE que hayan acudido a "ir de caza" apunta a aspectos importantes, mutuamente interrelacionados, de este colectivo: escaso número, escasa visibilidad, escasa aceptabilidad ético-moral y, de este modo, escasa legitimidad social.

\section{“El Proyecto es Mío pero...”: Ventajas e Inconvenientes de la Vía del "Donante Conocido"}

Dos de nuestras MSPE han accedido a la maternidad a través de "donante conocido", un término que en España, donde no cabe la reproducción asistida si no es mediante donante anónimo (salvo que se trate del cónyuge/pareja de hecho), significa mantener relaciones sexuales con alguien con quien se pacta, de manera más o menos explícita, más o menos exhaustiva, los términos del futuro vínculo entre el "donante" y el niño nacido de esas relaciones. Un número de dos es, en efecto, muy pequeño dentro de una muestra de 52. Las MSPE que han optado por esta vía no son tampoco fáciles de localizar, y las razones de ello son semejantes a las antes expuestas para el caso del "ir de caza", sólo que estas mujeres se hallan en un peldaño más alto de la escala de legitimidad social: ellas "no engañan", pero se embarcan en un proceso que, por mucho que quieran prever y controlar, conlleva consecuencias muy inciertas tanto para el hijo/a como para la madre; unas consecuencias que son vistas como evitables en la medida en que actualmente las mujeres tienen a su alcance otros caminos menos arriesgados para acceder a la maternidad en solitario. Una prueba de la escasez y/o de la poca visibilidad de estas MSPE se puede hallar, por ejemplo, en el hecho de que una de nuestras entrevistadas que ha seguido esta vía del "donante conocido" nos haya pedido que la pongamos en contacto con otras que también lo hayan hecho puesto que ella, que lleva años frecuentando diversos espacios en que participan MSPE, no ha conseguido comunicarse con ninguna. A ello responde igualmente el que las MSPE por fecundación sexual entrevistadas en el marco de otras investigaciones (y sucede también con una de nuestra muestra: Cristal) no se ajusten estrictamente a esta tipología, sino que se trata de mujeres solas que se han quedado embarazadas accidentalmente, no de manera planeada, y luego han aceptado (eso sí, jubilosamente) la situación, como es el caso de las tres madres biológicas del estudio de González et al. (2008), para referirnos a uno realizado en España, y de la mayoría de las estudiadas por Hertz (2006: 3) en Norteamérica.

En los dos casos de "donante conocido" de nuestra muestra hay una cuestión de oportunidad que explica, al menos en parte, el que se recurra a esta vía de acceso a la maternidad: facilidad para conseguir (y/o oportunidad de) que un varón de confianza se preste a engendrar un hijo sin que, de modo concomitante, reclame derechos de paternidad. Así, una de estas MSPE (Nora) comenta que un amigo suyo se le había ofrecido, siendo ambos muy jóvenes, para esa eventualidad; y la otra (Esmeralda) tenía la seguridad de que "una antigua pareja", que no quería ser padre, estaría dispuesta, sin embargo, a colaborar en su proyecto de maternidad en solitario. Es más, en este segundo caso, lo fácil que le resulta encontrar a alguien que acepte desempeñar el papel de "donante conocido" es lo que la anima a escoger esta vía de acceso a la maternidad puesto que, como se desprende de sus palabras, no se siente inclinada por ninguna de ellas en particular, estando convencida, además, de que habría querido igual a un hijo adoptado que a uno biológico. Nora, en cambio, prefiere la maternidad biológica porque, según dice, "tenía ganas realmente de vivir el embarazo", y opta por la fecundación sexual debido a que su "donante conocido" acepta sin restricciones la condición de ser sólo eso, es decir, sin reclamar un estatus de "padre":

Vamos, la idea era que yo iba a tener un hijo del que me iba a ocupar yo, iba a registrar yo a nivel legal y que su papel era el del donante, y que la niña se iba a criar conociendo que ella no tenía un papá, puesto que era un donante, no un papá. No obstante, si en el futuro ella quería o él quería investigar, pues, un poco sobre sus orígenes biológicos y eso, pues, que él estaba abierto a hablar con ella. Y me parecía también bonito que pudiera hacerlo, además. Que aunque rara, era una historia también bonita para ella, es decir: "Los dos hemos querido que nazcas, y hemos pensado que ésta es la mejor familia para ti” (Nora, 30-35 años, soltera, estudios 
universitarios, trabajo socio educativo, una

hija de 0-5 años con "donante conocido").

Sí piensa, sin embargo, en la posibilidad de acudir a la adopción internacional que, según asegura, desecha por "las connotaciones" que ésta tiene; unas "connotaciones" que parecen aludir a la injusticia que conlleva, en un marco de desigualdades estructurales, la circulación de niños desde el Tercer al Primer Mundo, si bien su discurso no es claro a este respecto.

En cuanto a Esmeralda, que baraja tres opciones para llegar a ser madre (adopción internacional, fecundación asistida y "donante conocido"), excluye la primera ya no por cuestiones ideológicas, sino a causa de la larga duración y la complejidad del proceso burocrático que comporta actualmente esta vía de acceso a la maternidad, sobre todo cuando se trata de adoptantes individuales. La razón que alega para no iniciar un proceso de inseminación artificial es la creencia de que no hay "control sanitario" de los donantes y de que no se tiene posibilidad, al ser anónima la donación, de localizarlos en el caso de que el hijo padezca alguna enfermedad transmitida genéticamente; creencia que no es corroborada por la legislación española sobre reproducción asistida.

La idea de que los genitores no tienen interés y/o no intentarán ejercer el rol de padres es -como se ha señalado- la que anima a algunas MSPE a recurrir al "donante conocido". Con todo, no todas negocian de la misma manera y con igual grado de detalle esta situación. Algunas, como es el caso de Esmeralda, permiten incluso que sus partenaires reconozcan su paternidad cuando inscriben el nacimiento del hijo/a en el Registro Civil, lo cual -según confiesan- no deja de ocasionarles "complicaciones" debido a que, al mismo tiempo, reclaman algunos márgenes de decisión sobre la vida del niño/a:

Creo que es más complicado porque, aunque el proyecto es tuyo, no deja de haber una tercera persona que de vez en cuando puede incordiar... con todo su derecho, ¿no? [E: ¿Y cómo se lo planteaste?] Quizá debería haberlo planteado de una manera más fría, pero no. Nos conocíamos lo suficiente como para pensar que esto no iba a generar problemas, pero sí, sí genera problemas. [E: ¿A qué te refieres?] Pues, porque el proyecto es mío y mi hijo vive conmigo, pero al estar reconocido... Yo creo que, de todo el proceso, eso sería lo único que cambiaría, porque tienes a esa tercera persona que está ahí y... hay que tenerla en cuenta (Esmeralda, 35-40 años, soltera, estudios universitarios, técnica, una hija de 0-5 años con "donante conocido").

El riesgo de que el "donante conocido" quiera cambiar lo implícita o explícitamente pactado, y pida ejercer de "padre", planea como una espada de Damocles sobre cualquier proyecto monoparental que aspire a mantenerse como tal, de ahí que unas mínimas dosis de realismo obliguen a preverlo en todos los casos:

Sí, esa posibilidad también la atamos cuando hablamos. No era miedo, sino tener en cuenta que eso podía ocurrir, y que mi planteamiento inicial era: yo quiero tener un niño yo sola y lo que le pedía era ayuda para la concepción, pero dejando abierta la puerta -más que nada porque no me parecía realista cerrarla sin saber cómo iba a reaccionar realmente cuando la niña naciera- a que, en el peor de los casos, pues, nos tendríamos que entender como cualquier pareja que se separa... o sea, si él hubiera cambiado (de idea) a lo largo del embarazo o al nacer la niña (Nora, 30-35 años, soltera, estudios universitarios, trabajo socioeducativo, una hija de 0-5 años con "donante conocido").

\section{"Tío, me vienes en el Peor Momento": la Preservación de la Autonomía del Proyecto Familiar Monoparental}

La posible reclamación de la paternidad es, de hecho, el principal inconveniente mencionado por las MSPE que han optado por el "donante conocido". Y es también el motivo más destacado que otras MSPE aducen para haber rechazado esta vía de acceso a la maternidad en solitario, siendo así no sólo entre las mujeres que forman parte de nuestra muestra, sino igualmente entre las participantes en otros trabajos tanto periodísticos (Jimeno 2000:37) como científico-sociales (Jordana 2007:55) realizados en España. Ello se debe, desde nuestro punto de vista, a que las MSPE emprenden un proyecto familiar monoparental que, al margen de la vía de acceso a la maternidad que hayan seguido y de la 
preferencia que, en algún momento de sus vidas, hayan mostrado por hacerlo en solitario o en pareja, se resisten a abandonar una vez que comprueban que solas pueden llevarlo adelante; evitando a partir de entonces compartir tanto la responsabilidad como la toma de decisiones sobre los hijos, sea con el progenitor de éstos sea, cuando no coinciden, con la persona con la que han podido establecer una relación de pareja antes o después de ser madres.

$\mathrm{Y}$ el hecho es que ahora, ; casualidades de la vida!, justo cuando estoy con la in vitro, pues, aparece un chico. Ahora estoy muy a gusto, estamos muy bien, me está apoyando muchísimo durante el embarazo y quiere ser padre. O sea, a mí ahora me descoloca. Digo: "Mira, tío, me vienes en el peor momento" porque, vale, yo quiero una pareja y disfrutar de lo bueno de tener pareja, pero no quiero que eso implique sufrimiento a mi hijo. [...] Yo creo que una vez tomas la decisión de este proyecto en solitario, es que eres como muy... ia ver cómo lo explico!, es igual que cuando estás casada, que parece que ir sola de compras es: "iQué horror!", o ir a una boda, irte de vacaciones, comprarte un coche, comprarte una casa... pero cuando ya haces ciertas cosas, ya es como: "Yo no quiero ir con nadie más" (Norma, 35-40 años, divorciada, estudios secundarios, directora de entidad privada, reproducción asistida).

No compartimos la idea-sostenida, por ejemplo, por Jordana (2007:129)- de que las MSPE, cuando culminan su deseo de ser madres, se embarcan en "un proyecto de paternidad no descartando la posibilidad de encontrar pareja en un futuro con la que compartir su descendencia”. El hecho de que estén abiertas a mantener una relación de pareja (como declaran, en efecto, cuando se les pregunta al respecto) no significa que, tras tener a sus hijos, estén interesadas en desarrollar "un proyecto de paternidad" si por ello se entiende que están dispuestas a otorgar al partenaire un rol de padre de sus hijos.

[E: Suponiendo que encuentres una pareja y que él quisiera adoptarlo...] Mira, si mi hijo es mío, si luego me separo, mi hijo es mío. A ver, que si ese niño establece una relación con esa persona, incluso no me negaría a compartirlo fines de semana, pero tu hijo es tuyo. Hombre, si es alguien que quiere adoptarlo porque: "Mira, no he tenido hijos. No me importa adoptarlo". Bueno, a día de hoy mi respuesta inicial sería que no (Crista, 30-35 años, soltera, estudios universitarios, ingeniera, reproducción asistida).

Así, las mujeres de nuestra muestra que han comenzado una relación de pareja tras haber alcanzado su objetivo de ser madres ( 6 de las 52 entrevistadas) ponen de manifiesto justo lo contrario, esto es, que siguen manteniendo separados ambos proyectos: el de maternidad/ filiación, de un lado, y el de emparejamiento/matrimonio, de otro. El reconocer, como hacen la mayoría de las MSPE, que la toma de decisiones sobre la crianza y la educación de los hijos supone una gran responsabilidad que, de ser compartida, se haría más llevadera no es óbice para que, al mismo tiempo, se resistan en la práctica a compartir dicha responsabilidad y, en general, las funciones paternas con sus parejas cuando las tienen. Todo ocurre como si la ventaja de compartir estas funciones la situaran en una familia biparental que, de tan idealizada, no la acabaran de identificar con ninguna realmente existente.

Algunas MSPE destacan no sólo la voluntad, sino también la deseabilidad de encargarse en solitario de la crianza y la educación de los hijos, de que éstos sean sólo "suyos", de ahí que traten de evitar con los medios a su alcance el riesgo de que el progenitor pueda reclamar la paternidad. En unos casos, lo hacen desechando la vía del "donante conocido" y recurriendo a la adopción internacional o a la fecundación asistida con donante anónimo como vías alternativas de acceso a la maternidad; y, en otros, negociando con el "donante conocido" -como se ha dicho-los términos de su relación presente y futura con la mujer y los hijos habidos con ella. Por otra parte, es cierto que, en los relatos de otras MSPE, aparece la idea de que si ellas pueden encontrar una pareja después de haber tenido a sus hijos, éstos pueden conseguir un padre de ese mismo modo. No obstante, esta idea surge casi siempre cuando aluden a la respuesta que podrían dar (o han dado) a las personas que hacen comentarios indiscretos sobre la "ausencia de un padre" en sus familias, es decir, que hacen uso de ella sobre todo para atajar opiniones impertinentes sobre su modelo familiar. 
Y, además, alguna gente a lo mejor te dice: “`Ay, el pobre niño no tendrá padre!”, y les digo: “¡Bueno, ¿y quién me dice a mí que pasado mañana no conozco a alguien?". [E: ¿Te lo ha comentado ya gente eso, así?] Sí, así: “¡Ay, pobrecito!”, “¡Cómo que pobrecito!"(risa). (Manuela, 40-45 años, soltera, estudios universitarios, traductora, adopción en Etiopía).

Ello confirma lo que -como se ha visto más atrás- sostienen autoras como Szapiro y FéresCarneiro (2002) o González et al. (2008), en el sentido de que las MSPE estructuran sus proyectos familiares y, en general, sus proyectos vitales en torno a valores como la independencia y la libertad, lo que pone de manifiesto a su vez que han interiorizado y aplicado a la configuración de sus vidas los mandatos socialmente establecidos para las mujeres de su generación (Rivas et al. 2010).

\section{Sobre la Confusión de Roles y otros Inconvenientes del "Donante Conocido"}

Hay MSPE que explican el haber descartado la vía del "donante conocido" añadiendo una razón más a las antes expuestas: se trata de la confusión de roles que, en su opinión, se generaría en estos casos (¿es sólo donante?, ¿padre del hijo/a?, ¿amigo o amante de la madre?), ya se mire desde la perspectiva de la mujer:

No se lo planteé a ninguno, pero pensé lo del amigo y, sobre todo, en la cantidad de amigos gays que posiblemente accederían, pero se lo dices a un amigo y todo estupendo, no tiene ninguna obligación, pero luego: "Que si hoy te lo dejo", "Me lo dejas", patatín. [...] Y si tienes algún problema económico, a la larga también dices: "Échame una mano y tal". Y luego él, aunque no tenga ninguna responsabilidad... pero un niño engancha y se va a ir enganchando, y te va a pedir más y, al final, vas a tener problemas: "¿Y cómo están los abuelos y tal?”. En fin, no sé, lo veía complicado. Con lo cual al haber esa facilidad (de hacerlo con donante anónimo), que tú escribes un contrato, lo veía como lo más cómodo, lo más sano para el donante, para la madre biológica y para el niño (Rosaura, 40-45 años, soltera, estudios universitarios, periodista, una hija de 5-10 años por reproducción asistida).

O se contemple desde la perspectiva del hijo/a, al que se le pondría en una situación delicada a la hora de entender su relación con la persona que, siendo su progenitor, no es su padre pero tampoco un mero conocido de la familia. Ello, según lo ven las entrevistadas, puede provocar además de problemas psicológicos en las personas involucradas, una gran incertidumbre acerca de cómo puede desarrollarse en el futuro un vínculo que, de entrada, es poco claro y cuyas consecuencias, por tanto, resultan difíciles de prever:

Luego sí, tuve ofertas de tres hombres conocidos, y las desestimé, porque ahí sí que me lo planteé ya de otra manera y empecé a pensar: "Bueno, a ver, es complicado ya tener un hijo sola, pero esto de que haya un padre pero que no haya, que exista pero que no exista, es mucho más complicado básicamente para mi hija". Son amigos que ella conoce, ¿y yo qué le tenía que decir a mi hija?: "Sí, este señor verdaderamente es tu padre, pero como si no lo fuera". Y luego, además, cualquiera sabe qué vínculo se hubiera creado entre mi hija y este señor: ¿ninguno?, ¿alguno?, ¿él querría en algún momento ejercer de padre? (Angelina, 45-50 años, soltera, estudios universitarios, empleada, una hija de 5-10 años por reproducción asistida).

Mientras que buena parte de las mujeres que terminan escogiendo la fecundación asistida se plantean la opción del "donante conocido" como una de sus posibles vías de acceso a la maternidad, tal vez debido a su preferencia por la reproducción biológica, muy pocas de las que acuden a la adopción confiesan haber pensado seria y detenidamente en ella (de hecho, sólo tres de las 33 adoptantes entrevistadas), pero - eso sí- dicen haberla rechazado por razones parecidas. Así, hay casos, como el de Luz o el de Celina, en que la vía del "donante conocido" podría haber constituido una solución aceptable $\mathrm{y}$, desde luego, muy accesible para hacer frente a una situación sentimental compleja (pareja estable que no quiere o no puede ejercer de padre /versus/ mujer que, sin renunciar a esta pareja, persiste en 
ser madre), pero que ellas han dejado de lado a favor de la adopción internacional (una en China y la otra en Etiopía) con el fin de eludir la trama de "complicaciones" enumerada más arriba. Ese "dejar de lado" ha consistido, en el caso de Celina, en no barajar ni siquiera esa opción (sí la de interrumpir la convivencia con el hombre con quien había vivido durante 20 años, aun cuando continúa unida afectivamente a él); y en el de Luz, en no querer quedarse embarazada de su pareja pues ésta, al tener "una situación personal poco clara", no se sentía libre de reconocer públicamente su paternidad como tampoco su relación sentimental con ella, por lo que -según sus palabras- sólo habría podido cumplir el papel de padre "de manera camuflada" incluso ante el hijo/a. Ambos casos ponen de manifiesto, por otro lado, que si bien la facilidad de conseguir un "donante conocido" es un elemento importante a la hora de tomarse en serio esta vía de acceso a la maternidad, tal circunstancia no es suficiente, aunque sí necesaria, para que se opte por ella.

La verdad es que pensé en todas las opciones: inseminación, ligue por un día y demás, pero no me interesó ninguna. No me dejaba ningún buen sabor de boca. $[E$ : ¿No llegaste a intentar la reproducción asistida, por ejemplo?] Me informé pero nunca llegué a intentarlo, porque yo tenía... queda mal decirlo, ¿no?, pero tenía voluntario para intentar ese embarazo y tampoco quise, ¿no?, porque no iba a ser el padre de mi hija. [...] Él me acompañó al viaje a China a buscar a mi hija y él me apoyó. Muchas veces se lo digo: "No sé cómo te lo voy a poder agradecer", porque es cierto que, en todo el proceso, yo tuve un apoyo incondicional con él, pero siempre he tramitado sola, siempre ha sido mi responsabilidad, mi sueño y mi hija. Para mi hija, él es su príncipe, ipero sólo tiene mamá! (Luz, 40-45 años, soltera, estudios secundarios, administrativo, una hija de 5-10 años adoptada en China).

Hay, finalmente, alguna MSPE adoptante - como es el caso de Anuska- que, para justificar el no haber considerado ni siquiera como posibilidad el procedimiento del "donante conocido", ya no sólo aduce los motivos más frecuentes, es decir, los alusivos a la confusión de roles o al riesgo de que el progenitor reclame su paternidad, sino que presenta esta vía de acceso a la maternidad en solitario como "utilización de una persona", recurriendo así a una expresión que no deja de traslucir un juicio ético-moral y que, como se ha visto más atrás, otras MSPE restringen a los casos de "ir de caza", a aquellos en que no se comunica a los partenaires la intención de embarazarse.

Los principales inconvenientes que las MSPE aprecian en la opción del "donante conocido" tienen que ver, sin embargo -como se ha visto- con los aspectos que ponen límites o pueden amenazar potencialmente un proyecto monoparental que aspira a conservarse como tal, es decir, que ellas desean que permanezca bajo su cargo y responsabilidad, toda vez que no se puede privar legalmente al progenitor de su derecho a reclamar la paternidad si decide no seguir aceptando el pacto de no ejercerla, del mismo modo que no se puede privar al hijo/a de su derecho a conocer su identidad. Quedan liberadas así incertidumbres y vaguedades que, a modo de caja de Pandora, retan la estabilidad psíquica y relacional de las personas implicadas. El que las MSPE, al menos las aquí estudiadas, hagan hincapié precisamente en estos inconvenientes refuerza el cuestionamiento expuesto más atrás de la tesis de Jordana (2007:129) acerca de la búsqueda, posterior a la llegada o al nacimiento del hijo, de una pareja que haga las veces de padre.

\section{Conclusiones}

La monoparentalidad por elección se presenta como uno de los modelos familiares a través de los cuales las mujeres, principalmente en las dos últimas décadas, están dando forma a sus deseos de ser madres. Se trata de mujeres que, en su mayoría, tienen estudios universitarios y acceden a la maternidad en torno a los 40 años de edad, esto es, siendo ya maduras, puesto que no emprenden sus proyectos familiares hasta no considerar estabilizadas sus carreras profesionales y no haberse forjado una situación socioeconómica y socioafectiva que les permita mantener solas una familia. De esta manera, no sólo han obedecido -como se ha dicho- los mandatos sociales dirigidos a las mujeres de su generación, sino que han hecho suyos los valores del individualismo que caracterizan la sociedad contemporánea, operando a partir de ellos una construcción de género atravesada por ideas como las de previsión, independencia económica, 
libertad, responsabilidad, elección... o realización personal (cifra Beck-Gernsheim 2003; Szapiro y Féres-Carneiro 2002).

Se ha sostenido en las páginas precedentes que sólo una pequeña parte de las MSPE optan por la fecundación sexual planeada para constituir sus proyectos familiares, sea mediante el procedimiento de "ir de caza" sea mediante el de "donante conocido", y que ello responde a dos razones principales: (1) la existencia de una escala de aceptabilidad social de la maternidad en solitario que depende de la vía de acceso a la misma; y (2) los riesgos que se originan de la posibilidad, ineludible según la legislación española, de que el "donante conocido" o, en menor medida, el "genitor" quieran ejercer la paternidad, lo cual erosionaría, desde el punto de vista de las MSPE, aspectos de sus vidas que consideran valiosos: la autonomía de su proyecto familiar y la estabilidad psíquica tanto de ellas como de sus hijos/as.

La escala de aceptabilidad social de la que estamos hablando (que jerarquiza a las MSPE en una gradación que va desde la fecundación sexual -y dentro de ésta, desde "ir de caza" al "donante conocido"- a la reproducción asistida y de ésta a la adopción, es decir, según la vía de acceso a la maternidad que han seguido) se apoya de manera paralela en dos sistemas axiológicos diferentes. Uno, de corte tradicional, está basado en una serie de juicios morales alusivos a la sexualidad de las mujeres que penalizan de forma aguda a las solteras, en especial si su sexualidad aboca en un embarazo, y erige a la sociedad en instancia ante la que hay que responder por los propios actos. El otro sistema, de corte más moderno, hace hincapié en la autonomía valorativa de los sujetos. Así, por un lado, apela al precepto de asumir la responsabilidad de las decisiones que se toman, sobre todo cuando afectan a los derechos de terceras personas (para lo que atiende a la manera en que esas decisiones vulneran o, por el contrario, preservan dichos derechos en lo que se refiere ya no sólo a la madre, sino también al hijo/a y al genitor/donante) y, por otro, instituye no a la sociedad (a "lo que está bien visto") sino a los hijos/as como la instancia ante la que es preciso responder. El argumento de la menor "explicabilidad" de la fecundación sexual planificada, referido más atrás, forma parte de este segundo sistema axiológico, así como el que plantea que las madres son las responsables de las consecuencias negativas que, también para los hijos/as, se pueden derivar tanto de "ir de caza" como de la opción del "donante conocido".

El caso es que la fecundación sexual planificada, se juzgue desde un código axiológico u otro, entraña un desafío mayor que las otras vías de acceso a la maternidad en solitario para los principios de una ideología del parentesco que es hegemónica en nuestra sociedad, y que aparte de establecer como ideal la familia biparental con presencia de un padre y una madre, no ve con buenos ojos la sexualidad de las solteras ni que éstas se sirvan de los varones a modo de sementales, esto es, como objetos para procrear o como prescindibles en otros ámbitos de la vida familiar. Por ello, las MSPE, en general, desarrollan estrategias con las que buscan legitimar (Bock 2000) sus decisiones mediante la negación expresa de que quieran desafiar el papel del hombre o de que haya una actitud antimasculina en el origen de sus proyectos familiares. De hecho, el modelo con el que se comparan es el de la familia nuclear, constituida por un hombre y una mujer con roles de género que se complementan, con el que deben medirse para establecer su legitimidad y su derecho a existir (Ben-Ari y Weinberg-Kurnik 2007; Bock 2000; Hertz 2006).

Ello no quiere decir que la monoparentalidad por elección, al igual que otras nuevas formas familiares que están emergiendo en las sociedades contemporáneas, no cuestionen de facto algunos principios en los que se asienta dicho modelo (y, en general, el sistema de parentesco euroamericano u occidental, del que habla Schneider 1968), como sucede con el binomio sexualidad(/pareja)-filiación(/paternidad), que es objeto de disociación por parte de las MSPE no sólo cuando acuden a la reproducción asistida o a la adopción para constituir sus familias, sino también cuando optan por la fecundación sexual puesto que, en los tres casos, separan su proyecto de maternidad de su proyecto de pareja al igual que separan la figura de genitor de la figura de padre (Jociles y Rivas 2010a) ${ }^{7}$, si bien estas separaciones corren el riesgo de anularse si, como se ha dicho, el progenitor o la pareja reclaman la paternidad del hijo/a. En este riesgo es donde, por otro lado, hemos hallado la otra explicación del escaso número de mujeres que escogen la fecundación sexual mediante "donante conocido" como vía para llegar a ser madres, toda vez de convertirse en realidad esa reclamación, perderían el control sobre su proyecto familiar y, por ende, la autonomía a la hora de decidir sobre la crianza y educación de los hijos/as. 
No obstante, si el riesgo existe y es percibido como tal por las MSPE, es porque éstas han disociado previamente tanto unos proyectos (maternidad/ pareja) como unas figuras paternas (genitor/padre) que, en el referido sistema cultural euroamericano, aparecen íntimamente unidos.

Según Schneider (1968), las concepciones dominantes sobre el parentesco en el sistema cultural euroamericano tienen como símbolo central la cópula sexual, expresión del amor entre marido y mujer y origen de los "auténticos parientes", los de sangre, vinculados por naturaleza al compartir esta substancia biogenética. Se trata de un modelo que asocia la sexualidad a la reproducción, la reproducción a las relaciones heterosexuales, las relaciones heterosexuales al matrimonio, el matrimonio a la familia y la familia al modelo nuclear de clase media. Schneider destaca, además, que estamos ante unas concepciones de la relación entre lo social y lo biológico, entre la naturaleza y la cultura, que es particular de la sociedad euro-americana, evidenciando la no transferibilidad de las mismas al dominio del parentesco de otras sociedades. En este sentido, nuestra investigación ha querido evidenciar que tampoco son válidas para la comprensión de lo que está ocurriendo, en las propias sociedades occidentales, con las nuevas formas de familia o, más concretamente, con la monoparentalidad por elección (Jociles y Rivas 2010b). Así, en este artículo, hemos tratado de mostrar que las MSPE subvierten principios básicos del sistema euroamericano de parentesco cuando recelan de la opción del "donante conocido" o cuando se resisten a compartir la crianza y educación de sus hijos/as con sus parejas.

Para finalizar, vamos a traer a colación una cuestión metodológica que estimamos básica para construir un conocimiento socioantropológico válido y riguroso: no reconstruir exhaustivamente el espacio de los diferentes puntos de vista sobre una temática determinada (aquí la monoparentalidad por elección), así como no considerar las funciones sociales, siempre cambiantes según los contextos de enunciación, que los discursos desempeñan o las complejas relaciones que se establecen entre éstos y las prácticas, puede ocasionar que se olviden aspectos importantes para entender cabalmente el sentido de los enunciados de los sujetos y de los colectivos sobre los que se investiga. Ello es lo que sucede, en nuestra opinión, con la idea de que las MSPE no hacen sino invertir la secuencia de construcción de un proyecto familiar convencional (pareja/matrimonio-hijos/filiación); idea que se apoya en la constatación de que quienes no están emparejadas afirmen estar "abiertas" a estarlo una vez hayan visto cumplido su deseo de maternidad. Hemos puesto de relieve que este planteamiento no tiene en cuenta que hay MSPE que niegan expresamente que estén dispuestas a que sus parejas, en el supuesto de tenerlas, asuman la paternidad de sus hijos, con la cesión de capacidad de decisión sobre sus vidas que ello conllevaría; y sobre todo ignoran que el desarrollo mismo del proyecto monoparental constituye una experiencia empoderadora de las mujeres, de modo que cuando comprueban a través de él que son capaces de sacarlo adelante, se redobla su resistencia a dicha cesión, por lo que un número significativo de las MSPE que están (o han estado) emparejadas sostienen que sus hijos, a pesar de esa circunstancia, son (y han sido) "sólo suyos" o tienen (y han tenido) "sólo mamá".

Agradecimentos: A los evaluadores anónimos que con sus comentarios ayudaron a mejorar este artículo.

\section{Referencias Citadas}

Alberdi, I. 1999. La Nueva Familia Española. Taurus, Barcelona.

Augé, M. 1996. El Sentido de los Otros. Actualidad de la Antropología. Paidós, Barcelona.

Badinter, E. 2011. La Mujer y la Madre. La Esfera de los Libros, Madrid.

Beck, U. y E. Beck-Gernsheim 2003. La Individualización. El Individualismo Institucionalizado y sus Consecuencias Sociales y Políticas. Paidós, Barcelona.

Beck-Gernsheim, E. 2003. La Reinvención de la Familia. En Busca de Nuevas Formas de Convivencia. Paidós, Barcelona.
Ben-Ari, A. y G. Weinberg-Kurnik 2007. The dialectics between the personal and the interpersonal in the experiences of adoptive single mothers by choice. Sex Roles 56:823-833.

Bock, J.D. 2000. Doing the right thing? Single mothers by choice and the struggle for legitimacy. Gender and Society 14:62-86.

Branham, E. 1979. One parent adoptions. Children 17:103-107.

Castanho, M.A. 2008. O planejamento familiar, o biodireito e a exclusão social, uma análise acerca da produção independente. Revista Eletrônica da Ordem dos Advogados do Brasil, Seção do Paraná 1:136-164. 
Dauster, T. 1987. Nome de Família: Maternidade Fora do Casamento e o Princípio de Filiação Patrilinear. Tesis doctoral inédita. Programa de Pós-Graduação em Antropologia Social, Museu Nacional. Universidade Federal do Rio de Janeiro.

Davies, L. y P. Rains 1995. Single mothers by choice? Families in Society 76 (9): 543-550.

Dougherty, S. A. 1978. Single adoptive mothers and their children. Social Work july: 311-314.

Dumont, L. 1987. Ensayos sobre el Individualismo. Una Perspectiva Antropológica sobre la Ideología Moderna. Alianza, Madrid.

González, M.M., I. Jiménez, B. Morgado y M. Díez 2008. Madres Solteras por Elección. Análisis de la Monoparentalidad Emergente. Instituto de la Mujer (Ministerio de Igualdad), Madrid.

Groze, V. 1991. Adoption and single parents. A review. Child Welfare League of America LXX:321-332.

Héritier, F. 2007. Masculino / Femenino. Disolver la Jerarquía. FCE, Buenos Aires.

Herrera, M. y V. Spaventa 2004. Familia monoparental, desmonoparentalidad y adopción. XI Encuentro Nacional y III Regional "Mujer y Justicia". Buenos Aires.

Hertz, R. 2006. Single by Chance, Mothers by Choice: How Women Are Choosing Parenthood Without Marriage And Creating The New American Family. Oxford University Press, New York.

Hertz, R. y F.I. Ferguson 1998. Only one pair of hands: ways that single mothers stretch work and family resources. Community, Work \& Family 1:13-37.

INE 2004. Cifras INE. Boletín Informativo del Instituto Nacional de Estadística. Cambios en la Composición de Los Hogares, Censo 2001.

Inglehart, R. 1990. Culture Shift in Advanced Industrial Society. Princeton University Press, Princeton.

Jiménez, A.B. 2005. Modelos y Realidades de la Familia Actual. Ed. Fundamentos, Madrid.

Jimeno, C. 2000. Hijos sí; maridos no. En cinco años más de 200 mujeres sin pareja han optado en España por la inseminación artificial. El País, 13 de febrero, 37.

Jociles, M.I. y A.M. Rivas 2009. Entre el empoderamiento y la vulnerabilidad: la monoparentalidad como proyecto familiar de las MSPE por reproducción asistida y adopción internacional. Revista de Antropología Social 18:127-170.

Jociles, M.I. y A.M. Rivas 2010a. ¿Es la ausencia del padre un problema? La disociación de los roles paternos entre las madres solteras por elección. Gazeta de Antropología 26 (1): artículo 04.

- - - 2010b. Motivaciones genéticas y experienciales: el discurso de las MSPE sobre la fecundación asistida como vía de acceso a la maternidad en solitario. Alteridades 20:107-124.
Jordana, Ó. 2007. La Maternidad Voluntariamente Sola en Barcelona: Una Aproximación Antropológica. Tesis doctoral inédita. Departamento de Antropología Social. Universidad de Barcelona.

Klock, S.C., M.C. Jacob y D. Maier 1996. A comparison of single and married recipients of donor insemination. Human Reproduction 11:2554-2557.

Leite, E. 2003. Famílias Monoparentais: A Situação Jurídica de Pais e Mães Solteiros, de Pais e Mães Separados e Dos Filhos na Ruptura da Vida Conjugal. Revista dos Tribunais, São Paulo.

Mannis, V. 1999. Single mothers by choice. Family Relations 48:121-128.

Mechanek, R., E. Klein y J. Kuppersmith 1988. Single mothers by choice: A family alternative. En Women, Power, And Therapy: Issues for Women, editado por M. Braude, pp. 263-281. Haworth Press, New York.

Murray, C. y S. Golombok 2005. Going it alone: solo mothers and their infants conceived by donor insemination. American Journal of Orthopsychiatry 75:242-253.

Potter, A.E. y P.K. Knaub 1988. Single motherhood by choice: a parenting alternative. Lifestyles: Family and Economic Issues 9:240-249.

Poveda, D., M.I. Jociles y A.M. Rivas 2011. Monoparentalidad por elección: procesos de socialización de los hijos/as en un modelo familiar no convencional. Athenea Digital 11:133-154.

Rivas, A.M., M.I. Jociles y B. Moncó 2011. Las madres solteras por elección. ¿Ciudadanas de primera y madres de segunda? Revista Internacional de Sociología 69:121-142.

Shireman, J.F. 1995. Adoptions by single parents. Marriage \& Family Review 20:367-388.

- - - 1996. Single parent adoptive homes. Children and Youth Savices Review 18:23-36.

Siegel, J.M. 1995. Looking for Mr. Right? 'Older single women who become mothers'. Journal of Family Issues 16:194-211.

- - - 1998. Pathways to single motherhood: Sexual intercourse, adoption, and donor insemination. Families in Society 79:75-82.

Schneider, D.M. 1968. American Kinship: A Cultural Account. Prentice-Hall, Englewood Cliffs.

Szapiro, A.M. y T. Féres-Carneiro 2002. Construções do femenino pós anos sessenta: o caso da maternidade como produçao independente. Psicologia: Reflexao e Critica 5:179-188.

Tort, M. 1995. Désir d'enfant ou offre d'enfant? Cahiers de l'École des Sciences Philosophiques et Religeuses 17:59-69.

\section{Notas}

1 Consiguió apoyo económico en la convocatoria Santander/ Complutense para proyectos de investigación durante el periodo 2008-09, esto es, en una convocatoria de carácter competitivo para equipos de investigación. El estudio se ha ampliado después gracias a un proyecto $\mathrm{I}+\mathrm{D}+\mathrm{i}$ titulado "Monoparentalidad por elección: estrategias de autodefinición, distinción y legitimación de nuevos modelos familiares" (FEM-2009-07717), concedido por el Ministerio de Ciencia e Innovación de España.

2 Traducción propia del original en portugués.

3 Para una visión de la evolución del conjunto de hogares no convencionales durante el periodo 1991-2001, ver Poveda et al. 2011. 
4 Para las representaciones que elaboran sobre la reproducción asistida, ver Jociles y Rivas 2010b.

5 Tres de nuestras entrevistadas son identificadas con pseudónimos para salvaguardar su anonimato y la confidencialidad de los datos. En el caso de post de foros, las personas aludidas son identificadas mediante sus nicks, cuando se usan en el texto, o letras mayúsculas, cuando se recurre al nombre real.

6 La dicotomía conocido/desconocido establece diferencias importantes en la predisposición a revelar o, por el contrario, ocultar los orígenes tanto a los hijos/as como al entorno social de las madres, esto es, tanto en el ámbito privado como en el público, debido principalmente a que el desconocimiento de (y/o la imposibilidad de conocer) quién es el genitor se considera una vulneración de los derechos de los hijos/as. Esta es la razón central por la que las MSPE que participan en los foros on-line mencionados en Metodología, así como las que forman parte de la asociación denominada "Madres Solteras por Elección" (con sede en Madrid), están discutiendo en estos momentos sobre la conveniencia o no de que la legislación española sobre reproducción asistida siga protegiendo el anonimato de los donantes, al contrario de lo que ha sucedido a este respecto en otros países, como Suecia, Austria, Suiza, Reino Unido, Nueva Zelanda, Noruega, Holanda, los territorios australianos de Australia Occidental y Victoria, Islandia, Bélgica o Estados Unidos de Norteamérica. Y es también -como se ha dicho- una razón por la que, en el caso de la fecundación sexual, consideran preferible la opción del "donante conocido" sobre la de "ir de caza", que es lo que estamos tratando en este artículo.

7 En este artículo se aborda la des-problematización de que es objeto la ausencia de un padre en sus familias, para lo que las MSPE recurren, entre otras cosas, a la disociación de las figuras de genitor/ donante/ padre/ pareja, además de implicar a sus hijos/as en un proceso de normalización de sus modelos familiares en diferentes contextos de interacción (escuela, grupos de amigos, familia extensa, entre otros). 
